\title{
Modeling Haze Problems in the North of Thailand using Logistic Regression
}

\author{
Busayamas Pimpunchat ${ }^{1}$, Khwansiri Sirimangkhala $^{1}$ \& Suwannee Junyapoon ${ }^{2}$ \\ ${ }^{1}$ Industrial Mathematics Research Unit \& Department of Mathematics, \\ Faculty of Science, King Mongkut's Institute of Technology Ladkrabang, \\ Bangkok 10520, Thailand \\ ${ }^{2}$ Department of Chemistry, Faculty of Science, \\ King Mongkut's Institute of Technology Ladkrabang, Bangkok 10520, Thailand. \\ Email: knbusaya@kmitl.ac.th
}

\begin{abstract}
At present, air pollution is a major problem in the upper northern region of Thailand. Air pollutants have an effect on human health, the economy and the traveling industry. The severity of this problem clearly appears every year during the dry season, from February to April. In particular it becomes very serious in March, especially in Chiang Mai province where smoke haze is a major issue. This study looked into related data from 2005-2010 covering eight principal parameters: $\mathrm{PM}_{10}$ (particulate matter with a diameter smaller than 10 micrometer), $\mathrm{CO}$ (carbon monoxide), $\mathrm{NO}_{2}$ (nitrogen dioxide), $\mathrm{SO}_{2}$ (sulphur dioxide), RH (relative humidity), NO (nitrogen oxide), pressure, and rainfall. Overall haze problem occurrence was calculated from a logistic regression model. Its dependence on the eight parameters stated above was determined for design conditions using the correlation coefficients with $\mathrm{PM}_{10}$. The proposed overall haze problem modeling can be used as a quantitative assessment criterion for supporting decision making to protect human health. This study proposed to predict haze problem occurrence in 2011. The agreement of the results from the mathematical model with actual measured $\mathrm{PM}_{10}$ concentration data from the Pollution Control Department was quite satisfactory.
\end{abstract}

Keywords: forecasting; haze problem; multivariate logistic regression; mathematical model; $P M_{10}$.

\section{$1 \quad$ Introduction}

For the past decades, a thick particle haze that covers the Northern region of Thailand, i.e. Chiang Mai, Chiang Rai, Lamphun, Lampang, Mae Hong Son, Phayao, Phrae and Nan, has been causing serious air pollution problems during the dry season. [1] A haze crisis caused by the dry and stagnant weather conditions occurs every year in the dry season, from February to April, especially in March. These conditions produce dust particles smaller than 10 microns $\left(\mathrm{PM}_{10}\right)$ suspended in the atmosphere. During this period, a large amount of particulate matters are released into the atmosphere, including carbon monoxide $(\mathrm{CO})$, carbon dioxide $\left(\mathrm{CO}_{2}\right)$, volatile organic compounds (VOCs), 
carcinogenic polycyclic aromatic hydrocarbons (PAHs) [2]. The main emission source is biomass open burning, such as forest fires, solid waste burning, and agricultural residue field burning [3,4]. The air pollutants are trapped near ground level due to the meteorological conditions (e.g. stagnant air) and the basin-liked topography surrounded by high mountain ranges results in restricted pollution dispersion. In addition, low rainfall in dry season effect on violence of haze problem. For this reason, the leaching of smoke or dust particles in the air is low [4]. A report from the Pollution Control Department revealed that Chiang Mai province encounters ever longer and more serious smog problems.

During haze periods, the 24-hour average concentrations of particulate matter with an aerodynamic diameter smaller than 10 micron $\left(\mathrm{PM}_{10}\right)$ frequently exceed the Thailand National Ambient Air Quality Standard (NAAQS) of 120 micron [5]. Also, the Public Health Ministry of Thailand [1] has reported an increase in bronchial asthma and respiratory diseases in people living in these areas. In addition, these fine particles contain carcinogenic polycyclic aromatic hydrocarbons that can induce lung cancer [6]. The smoke haze episodes affect not only adverse health problems but also reduce visibility and cause economic sectors to decline, i.e. tourism, transportation, and agriculture. Therefore, the Thai government shows increasing concern to get the smoke haze problem under control [5].

The $\mathrm{PM}_{10}$ measurement method is complex and it takes a long time to analyze the results with a performance tool [7]. In order to simplify this process, we utilized a logistic regression analysis method for establishing the occurrence of haze. As the first step, we determined the main factors associated with the occurrence of haze in the Chiang Mai area. The second step was to establish a mathematical model to represent the occurrence of haze using the main factors from the logistic regression analysis. Lastly, we used the mathematical model to predict the occurrence of haze in the next year. This study can be used as guidance for monitoring haze problems in the northern region of Thailand.

\section{Study Data}

This study is based on an investigation of hourly measured data over a six-year period, from 2005 to 2010 . $\mathrm{PM}_{10}$ is one of five air pollutants that are used to measure air quality in Thailand. The Air Quality Index (AQI) is a number used by government agencies to communicate to the public how polluted the air is currently or how polluted it is forecasted to become. 


\subsection{Air Quality Index}

The Air Quality Index (AQI) is an indicator of air quality, based on air pollutants that have adverse effects on human health and the environment. The main pollutants for Thailand are: $\mathrm{O}_{3}, \mathrm{SO}_{2}, \mathrm{NO}_{2}, \mathrm{CO}$ and $\mathrm{PM}_{10}$. The maximum AQI from these five pollutants is an indicator of the air quality for a particular day or moment. The Pollution Control Department of the Ministry of Natural Resources and Environment is the organization in Thailand that measures the $\mathrm{AQI}$ and reports the results $[8,9]$.

The effects of air pollution on people's health can become a cause for concern, as shown Table 1. During the dry season of 2007, there was no rainfall for 6 months (November 2006 - April 2007). The occurrence of smoke haze affected a high $\mathrm{PM}_{10}$ concentration of up to 303.9 micron [4]. The number of patients infected with respiratory diseases and allergies increased dramatically according to a report from the Public Health Department of Chiang Mai province.

Table 1 Air Quality Index criteria in Thailand.

\begin{tabular}{cccc}
\hline $\begin{array}{c}\text { AQI } \\
\text { Values }\end{array}$ & $\begin{array}{c}\text { Level of Health } \\
\text { Concern }\end{array}$ & Colors & Meaning \\
\hline $0-50$ & Good & Blue & $\begin{array}{c}\text { Air quality is considered satisfactory, } \\
\text { and air pollution poses little or no risk. }\end{array}$ \\
\hline $51-100$ & Moderate & Green & $\begin{array}{c}\text { Air quality is acceptable; however, for } \\
\text { some pollutants there may be a } \\
\text { moderate health concern for a very } \\
\text { small number of people who are } \\
\text { unusually sensitive to air pollution. }\end{array}$ \\
\hline $101-200$ & Unhealthy & Yellow & $\begin{array}{c}\text { Members of sensitive groups may } \\
\text { experience health effects. The general } \\
\text { public is not likely to be affected. }\end{array}$ \\
\hline $201-300$ & Very unhealthy & Orange & $\begin{array}{c}\text { Everyone may begin to experience } \\
\text { health effects: members of sensitive } \\
\text { groups may experience more serious } \\
\text { health effects. }\end{array}$ \\
\hline $\begin{array}{l}\text { Over } \\
300\end{array}$ & Hazardous & Red & $\begin{array}{c}\text { Health alert: everyone may experience } \\
\text { more serious health effects. }\end{array}$ \\
\hline Source: Pollution Control Department (www.pcd.go.th) &
\end{tabular}

\section{$2.2 \quad \mathbf{P M}_{10}$}

$\mathrm{PM}_{10}$ is suggested as an indicator with relevance to the majority of the epidemiological data. It is extensively measured throughout the world [10,11]. As mentioned earlier, knowing the occurrence of $\mathrm{PM}_{10}$ from the ambient parameters is significantly necessary. The standard level of $\mathrm{PM}_{10}$ in Thailand is declared at 120 micron. However, during haze occurrence, 100 micron is set to 
monitor and alert people. In this study, $\mathrm{PM}_{10}$ was investigated in order to categorize haze occurrence response into 3 levels $(0,1$ and 2) using logistic regression analysis. The detection limits were 0-99, 100-119, and over 120 micron, respectively indicating: little health effect; more health effect and alert; more serious health effect. $\mathrm{PM}_{10}$ was implicated with associated factors for predicting the occurrence of haze.

\section{$3 \quad$ Methodology}

The procedure of this research was as follows:

Step 1: Collect data of $\mathrm{PM}_{10}, \mathrm{CO}, \mathrm{NO}, \mathrm{NO}_{2}, \mathrm{SO}_{2}, \mathrm{O}_{3}$, wind direction, temperature, relative humidity $(\mathrm{RH})$, pressure, wind speed and rainfall.

Step 2: Find the relationships between $\mathrm{PM}_{10}$ and others parameters by Pearson correlations for relationship classification into high, moderate, or low.

Step 3: Construct logistic regression for haze problem model using high and moderate relationships. Define response function on the basis of $\mathrm{PM}_{10}$ concentrations, reflecting the different ranges as: "little health effect (0-99)", "more health effect and alert (100-119)" and "more serious health effect (over 120)".

Step 4: Analysis and discussion of logistic regression model. Present goodness of fit by Pseudo $\mathrm{R}^{2}$.

Step 5: Consider level of health concern for $\mathrm{PM}_{10}$ levels in 2011 to indicate health effects.

\subsection{Logistic Regression Analysis}

Logistic regression or logit regression is a type of regression analysis used for predicting the outcome of a categorical dependent variable based on one or more predictor variables. That is, it is used for estimating the empirical values of parameters in a qualitative response model. The probabilities describing the possible outcomes of a single trial are modeled as a function of the predictor variables using a logistic function. Usually, logistic regression is used to refer specifically to problems in which the dependent variable is binary, which means that the number of available categories is two. Problems with more than two categories are referred to as multinomial logistic regressions or, if the multiple categories are ordered, as ordered logistic regressions [12,13]. Moreover, logistic regression measures the relationship between a categorical dependent variable and one or more independent variables that are usually continuous. The probability scores are utilized as the predicted values of the dependent variable [14]. 


\subsection{Mathematical Model}

Haze smoke problems normally occur in Northern Thailand for a short period from February to April each year, peaking in March. The factors relating to this problem correspond to 11 parameters $[9,12]$, i.e. $\mathrm{PM}_{10}, \mathrm{CO}, \mathrm{NO}, \mathrm{NO}_{2}, \mathrm{SO}_{2}, \mathrm{O}_{3}$, wind direction, temperature, relative humidity $(\mathrm{RH})$, pressure, wind speed, and rainfall. In order to identify the relationships between $\mathrm{PM}_{10}$ and the others parameters, the Pearson correlations were analyzed.

\subsubsection{Model Formulation}

The objective of modeling the relation between the occurrence of haze (dependent variable) and concentrations of gases with meteorological data (independent variables) is to estimate the probability of the former given the incidence of the latter. An explanation of logistic regression begins with an explanation of the logistic response function, which always takes on values between zero and one. Let $P_{i}$ denote the multinomial probability of an observation falling in the $j$ th category. Category $j$ is used as the base level of the method (any category can be taken as the base level). We want to find the relationship between this probability and $n$ explanatory variables, $x_{1}, x_{2}, \ldots, x_{n}$. The multinomial logistic regression model then is

$$
\ln \left(P_{i} / P_{j}\right)=\beta_{0 i}+\beta_{1 i} x_{1}+\ldots+\beta_{n i} x_{n}
$$

and $P_{1}+P_{2}+\ldots+P_{j}=1$

where $\beta_{0}, \beta_{1}, \ldots, \beta_{n}$ are model parameters for $i=1,2, \ldots, m$.

Since all the $P$ 's add to unity, this can be reduced to

$$
P_{i}=\frac{\exp \left(\beta_{0 i}+\beta_{1 i} x_{1}+\ldots+\beta_{n i} x_{n}\right)}{1+\sum_{k=1}^{j-1} \beta_{0 k}+\beta_{1 k} x_{1}+\ldots+\beta_{n k} x_{n}}
$$

For $i=1,2, \ldots, j-1$

$$
P_{j}=\frac{1}{1+\sum_{k=1}^{j-1} \beta_{0 k}+\beta_{1 k} x_{1}+\ldots+\beta_{n k} x_{n}}
$$

The model parameters are estimated by the method of maximum likelihood $[12,13]$. 


\subsubsection{Estimation of Model Parameters in Logistic Regression}

The regression coefficients are usually estimated through an iterative maximum likelihood method. Unlike linear regression with normally distributed residuals, it is not possible to find a closed-form expression for the coefficient values that maximizes the likelihood function, so an iterative process must be used instead [13].

The log likelihood functions for the multinomial logistic regression model are:

$$
\ln L=\sum_{i=1}^{N} \sum_{r=1}^{j-1}\left(y_{i r} \sum_{k=0}^{K} \beta_{k r} x_{i k}-n_{i} \ln \left(1+\sum_{r=1}^{j-1} \exp \left(\sum_{k=0}^{K} \beta_{k r} x_{i k}\right)\right)\right)
$$

where $Y_{i r}$ is a known, fixed constant value. Logistic regression models require a minimum of $\log$ likelihood to find parameters $\beta_{0}, \beta_{1}, \ldots, \beta_{n}$. Since Eq. (5) is nonlinear, Newton's method is used for this model. [14]

\subsubsection{Measurement of Relationships}

In linear regression, the squared multiple correlation $\mathrm{R}^{2}$ is used to assess goodness of fit, as it represents the proportion of variance in the criterion that is explained by the predictors. In logistic regression analysis, there is no agreed upon analogous measure but there are several competing measures, each with its own limitations [12]. Pseudo $\mathrm{R}^{2}$ is used to assess goodness of fit, as it represents the proportion of variance in the criterion that is explained by the predictors in the logistic regression analysis. The Pseudo $\mathrm{R}^{2}$ formula used here is:

$$
\text { Pseudo } R^{2}=\frac{-2 \log L_{\text {Null }}-\left[2 \log L_{\text {Model }}\right]}{-2 \log L_{\text {Null }}}
$$

where $L_{\text {Null }}$ is a likelihood function with only constants

$L_{\text {Model }}$ is a likelihood function with the predicted value defined

Pseudo $\mathrm{R}^{2}$ always takes on values between zero and one.

\section{$4 \quad$ Results and Discussion}

$\mathrm{PM}_{10}$ is an important variable that indicates the violence of a haze situation. In this study, we firstly found the correlation coefficient between $\mathrm{PM}_{10}$ and the concentrations of gases along with meteorological factors to formulate a model for predicting the occurrence of haze using a logit function. 


\subsection{Results of Correlation Coefficients}

Correlation analysis was used to approach the relationship between two or more variables by correlation coefficient ( $r$ ) values from -1 to 1 . A negative value represents a contrary relationship, whereas a positive value shows the same direction among the sets of variables [12]. The values were defined as follows: (i) $\mathrm{r}$ from 0.50 to 1.00 or from -0.50 to -1.00 was considered a high correlation; (ii) from 0.30 to 0.49 or -0.30 to -0.49 was considered a moderate correlation; (iii) from 0.10 to 0.29 or -0.10 to -0.29 was considered a low correlation; and (iv) zero represents no relationship.

From the above principle, we obtained seven main factors associated with the concentration of $\mathrm{PM}_{10}$, derived from the high and moderate correlation values, as shown in Table 2. Thus, the main factors associated with the $\mathrm{PM}_{10}$ concentration are $\mathrm{CO}, \mathrm{NO}_{2}, \mathrm{O}_{3}, \mathrm{RH}, \mathrm{SO}_{2}, \mathrm{NO}$ and pressure. We tried using only the high correlation group, which resulted in less accuracy than using both the high and moderate correlations.

Table 2 Correlation coefficients of all parameters.

\begin{tabular}{cccc}
\hline Factors & Correlation & Factors & Correlation \\
\hline $\mathrm{CO}$ & 0.6676 & Temperature & 0.0160 \\
$\mathrm{NO}$ & 0.3191 & $\mathrm{RH}$ & -0.6633 \\
$\mathrm{NO}_{2}$ & 0.8245 & Pressure & 0.3278 \\
$\mathrm{SO}_{2}$ & 0.4719 & Wind Speed & -0.0642 \\
$\mathrm{O}_{3}$ & 0.5576 & Wind Direction & -0.0865 \\
Rainfall & -0.2234 & & \\
\hline
\end{tabular}

In contrast to the independent variables $\left(X_{i}\right)$, which are quantitative variables, the dependent variable $(Y)$ is a qualitative variable. Moreover, the values of $Y$ were coded for the smog problems into 3 cases. The response function on the basis of $\mathrm{PM}_{10}$ concentrations reflects the different ranges as shown in Table 2 , where all the values of $\mathrm{CO}, \mathrm{NO}_{2}, \mathrm{O}_{3}, \mathrm{RH}, \mathrm{SO}_{2}, \mathrm{NO}$ are in $\mu \mathrm{g} / \mathrm{m}^{3}$ and pressure is in bar.

Let $\mathrm{P}_{1}$ be the probability that $0 \leq \mathrm{PM}_{10} \leq 99$, or, "little health effect"; $\mathrm{P}_{2}$ is the probability that $100 \leq \mathrm{PM}_{10} \leq 119$, or, "more health effect and alert"; and $\mathrm{P}_{3}$ is the probability that $\mathrm{PM}_{10} \geq 120$, or, "more serious health effect". Category 1 is the base level in our description of the method.

The logistic regression models of this study are:

$$
\ln \left(P_{2} / P_{1}\right)=\beta_{02}+\beta_{12} x_{1}+\ldots+\beta_{72} x_{7}
$$




$$
\ln \left(P_{3} / P_{1}\right)=\beta_{03}+\beta_{13} x_{1}+\ldots+\beta_{73} x_{7}
$$

and $P_{1}+P_{2}+P_{3}=1$

This can be reduced to:

$$
\begin{aligned}
& P_{1}=\frac{1}{1+\sum_{k=2}^{3} \beta_{0 k}+\beta_{1 k} x_{1}+\ldots+\beta_{7 k} x_{7}} \\
& P_{2}=\frac{\exp \left(\beta_{02}+\beta_{12} x_{1}+\ldots+\beta_{72} x_{7}\right)}{1+\sum_{k=2}^{3} \beta_{0 k}+\beta_{1 k} x_{1}+\ldots+\beta_{7 k} x_{7}}
\end{aligned}
$$

and $P_{3}=\frac{\exp \left(\beta_{03}+\beta_{13} x_{1}+\ldots+\beta_{73} x_{7}\right)}{1+\sum_{k=2}^{3} \beta_{0 k}+\beta_{1 k} x_{1}+\ldots+\beta_{7 k} x_{7}}$

where $x_{1}, x_{2}, \ldots, x_{7}$ are concentration of $\mathrm{CO}, \mathrm{NO}_{2}, \mathrm{O}_{3}, \mathrm{RH}, \mathrm{SO}_{2}$, pressure and $\mathrm{NO}$, respectively.

\subsection{Results of Coefficient Estimation}

The logistic regression models are

$$
\begin{gathered}
\ln \left(P_{2} / P_{1}\right)=0.896 x_{1}+0.205 x_{2}-0.052 x_{3}+0.068 x_{4}+0.113 x_{5} \\
-0.114 x_{6}+0.256 x_{7}-89.639 \\
\ln \left(P_{3} / P_{1}\right)=2.232 x_{1}+0.362 x_{2}-0.103 x_{3}+0.136 x_{4}+0.242 x_{5} \\
-0.136 x_{6}-0.06 x_{7}-188.344
\end{gathered}
$$

Considering the seven predictive variables that influence the occurrence of smog derived from $\mathrm{PM}_{10}$ concentration and considering the predictive ability of the logistic model, the variation of this haze problem model is $59.6 \%$ (Pseudo $\mathrm{R}^{2}=0.5960$ ). The accuracy of the model was $94.66 \%$.

Figure 1 shows the multinomial logistic regression of this model for 2011. The accuracy of the model for 2011 was 92.33\%. Figure 2 shows when high concentrations of $\mathrm{PM}_{10}$ affecting the haze situation advise monitoring and forecasting of criteria pollutants in the air during March and April in 2011. From the smog haze prediction for 2011 it can be seen that it is an important task to make how bad or good the air quality is for human health easily 
understandable and to assist in data interpretation for the decision making processes related to pollution migration measures and air quality management.

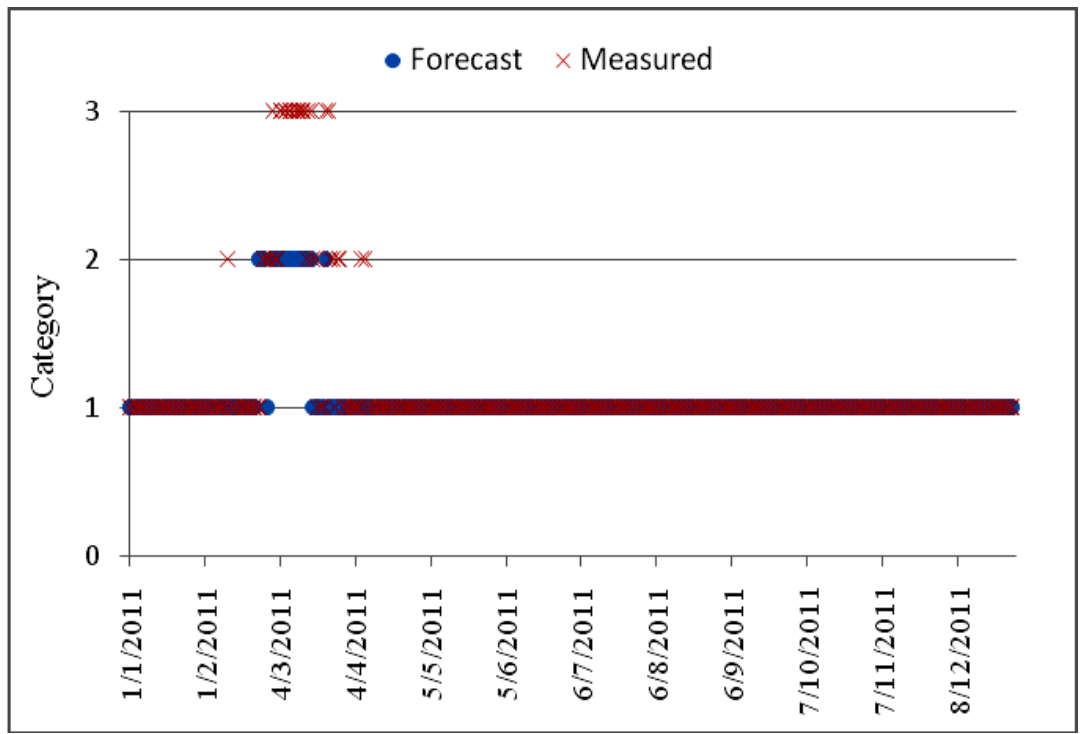

Figure 1 Multinomial logistic regression model in 2011.

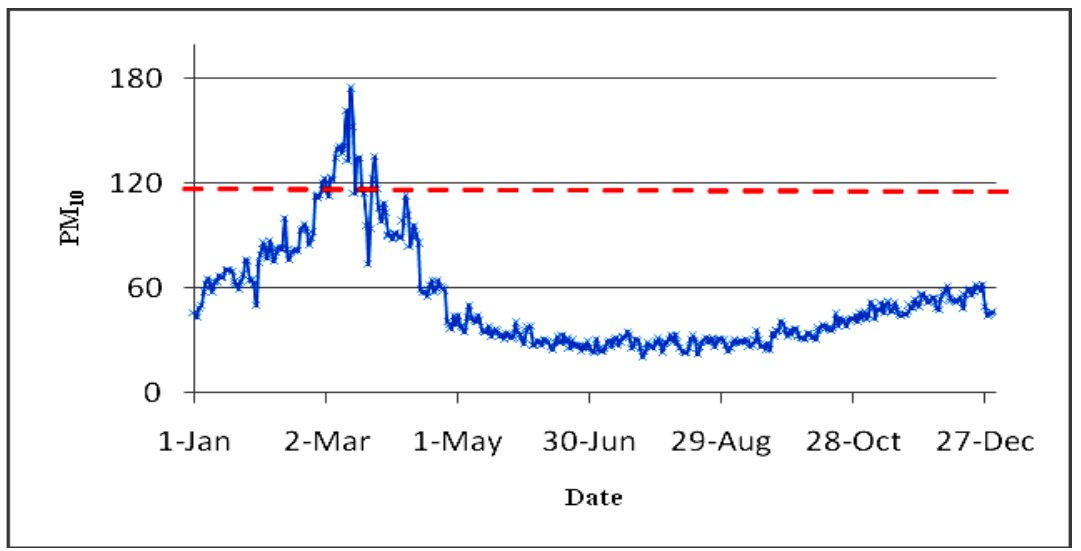

Figure 2 Plot of $\mathrm{PM}_{10}$ daily concentrations from PCD, Thailand in 2011.

Figure 3 shows that smog haze situations affecting the level of human health concerns could be classified into 3 levels of air quality: "Good" about $60 \%$ (219/365), "Moderate" about 31.23\% (114/365), and "Unhealthy" about 8.77\% $(32 / 365)$. A comparison between the observed values and the model's predicted values suggests that the model can be used for the prediction of daily $\mathrm{PM}_{10}$ concentrations in urban areas. 


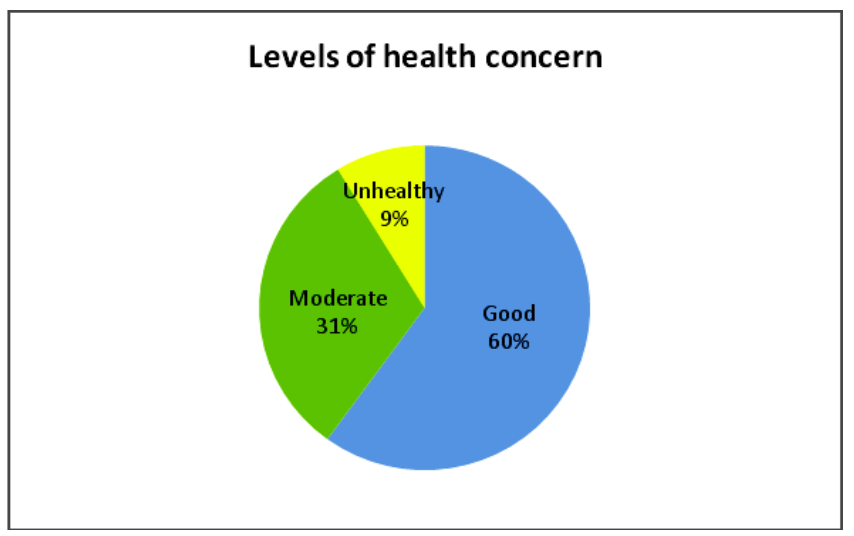

Figure 3 Level of Health Concern of $\mathrm{PM}_{10}$ in 2011.

\section{Conclusions}

A modeling effort was conducted in order to investigate human health concerns related to smoke haze for decision-making purposes. Logistic regression analysis was used as a tool for achieving the difficult task of predicting daily $\mathrm{PM}_{10}$ concentrations based on the main parameters affecting smog haze situations in Chiang Mai province. As a result it is believed that the derivation of $\mathrm{PM}_{10}$ concentrations from the parameters affecting smog haze situations should be considered as a tool for operational use in $\mathrm{PM}_{10}$ concentration forecasting, aiding the protection of the exposed population against short-term variations in particulate matter levels.

\section{Acknowledgements}

The authors would like to thank the Pollution Control Department in Thailand, which kindly provided valuable data. The financial support for this research project from the faculty of Science, King Mongkut's Institute of Technology Ladkrabang, Thailand is gratefully acknowledged.

\section{References}

[1] PCD (Pollution Control Department), http://www.pcd.go.th (6 July 2012).

[2] Phoothiwut, S. \& Junyapoon, S., Size Distribution of Atmospheric Particulate-bound Polycyclic Aromatic Hydrocarbons and Characteristics of PAHs during Haze Period in Lampang Province, Northern Thailand, Air Quality, Atmosphere \& Health, 6(2), pp. 397405, 2013. 
[3] Chantara, S., Sillapapiromsuk, S. \& Wiriya, W., Atmospheric Pollutants in Chiang Mai (Thailand) over a Five-year Period (2005-2009), their Possible Sources and Relation to Air Mass Movement, Atmospheric Environment, 60, pp. 88-98, 2012.

[4] Wiriya, W., Sillapapiromsuk, S. \& Chantara, S., PM10-Bound Polycyclic Aromatic Hydrocarbons in Chiang Mai (Thailand): Seasonal Variations, Source Identification, Health Risk Assessment and Their Relationship to Air-Mass Movement, Atmospheric Research, 124, pp. 109-122, 2013.

[5] PCD (Pollution Control Department), Maryland Department of the Environment, \& Chiang Mai Municipality, Chiang Mai Emission Inventory in Municipality and Neighborhood Area, Report of Ability of Federal and Local Government Official, Chiang Mai, 2002.

[6] Pengchai, P., Chantara, S., Sopajaree, K. \& Wangkarn, S., Tengcharoenkul, U. \& Rayanakorn, M., Seasonal Variation, Risk Assessment and Source Estimation of $P M_{10}$ and PM $M_{10}$-bound PAHs in the Ambient Air of Chiang Mai and Lumphun, Thailand, Environ. Monit. Assess., 154, pp. 197-218, 2009.

[7] Pollution Control Department, Manual Measurement of Dust in Ambient, Bangkok: Kochakorn Publishing, 2003.

[8] Rayanakorn, M., Haze and Air Pollution in Chiang Mai, Chiang Mai: Login Design Work, pp. 9-14, 2010.

[9] Jeremy, C., Air Pollution: An Introduction, London: E\&FN Spon, 1997.

[10] Kumer, A. \& Goyal, P., Forecasting of Daily Air Quality Index in Delhi, Science of the Total Environment, 409, pp. 5517-5523, 2011.

[11] World Health Organization, WHO Air Quality Guidelines Global Update 2005, Report on Working Group Meeting, Bonn, Germany, 18-20 October 2005.

[12] Kleinbaum, D.G., Logistic Regression: A Self-Learning Text, $3^{\text {rd }}$ ed., New York: Springer, 2010.

[13] Hilbe, J.M., Logistic Regression Models, Boca Raton: CRC Press, 2009.

[14] Hamilton, L.C., Statistics with Stata, Pacific Grove, CA: Brooks/Cole Publishing Company, pp. 137-145, 1990. 